\title{
A Picture of Change: Using Photovoice to Explore Social and Environmental Change in Coastal Communities on the Andaman Coast of Thailand
}

\author{
Nathan James Bennett ${ }^{1}$ and Philip Dearden ${ }^{2}$
}

This is the final post-print version of the following article prior to publication and should be cited as follows: Bennett, N. \& Dearden, P. (2013). A Picture of Change: Using Photovoice to Explore Social and Environmental Change in Coastal Communities on the Andaman Coast of Thailand. Local Environment: The International Journal of Justice and Sustainability, 18(9), 983-1001.

\begin{abstract}
Coastal communities experience a wide array of environmental and social changes to which they must constantly adapt. Further, a community's perception of change and risk has significant implications for a community's willingness and ability to adapt to both current and future changes. As part of a larger study focusing on the adaptive capacity of communities on the Andaman Coast of Thailand, we used Photovoice to open a dialogue with communities about changes in the marine environment and in coastal communities. This paper presents the results of two exploratory Photovoice processes and discusses prospects for using the Photovoice method for exploring social and environmental change. Changes examined included a number of broader environmental and social trends as well as ecological specifics and social particularities in each site. Participants also explored the social implications of environmental changes, the impacts of macro-scale processes on local outcomes, and emotive and active responses of individuals and communities to change. Photovoice is deemed a powerful method for: examining social, environmental, and socio-ecological change, triangulating to confirm the results of other scientific methods, revealing novel ecological interactions, and providing input into community processes focusing on natural resource management, community development, and climate change adaptation.
\end{abstract}

Keywords: environmental change, social change, marine environment, coastal communities, Photovoice

\section{Introduction and Overview}

Resource dependent coastal communities are often highly vulnerable to change events and at the same time are experiencing changes at an accelerated rate (Marshall et al. 2009). These changes include, for example, declines in fisheries, changes in regulatory frameworks for resource harvesting, different demands from global markets, shifts to new livelihoods, and natural hazards (e.g., Cinner et al. 2009). Climate change is arguably one of the most significant changes being experienced by many coastal communities, as climate related changes including intensifying storms, rising sea-levels, acidifying oceans, changing rainfall patterns, and ocean currents lead to a number of stressors on communities and on the ecosystems on which they rely (Parry and IPCC 2007). The ability of communities to adapt and respond to the changes that are brought about by a diverse array of change events determines their overall vulnerability and has implications for local and regional environmental sustainability. Social adaptive capacity - also called social resilience - refers to "the ability to respond to challenges through

\footnotetext{
${ }^{1}$ Nathan James Bennett, PhD Candidate, SSHRC and Trudeau Scholar, Marine Protected Areas Research Group, Department of Geography, University of Victoria, Victoria, Canada, njbennet@uvic.ca ${ }^{2}$ Philip Dearden, Professor and Chair, Marine Protected Areas Research Group, Department of Geography, University of Victoria, Victoria, Canada
} 
learning, managing risk and impacts, developing new knowledge and devising effective approaches" (Marshall et al. 2009, p. 7). Carpenter et al. (2001) argue that in explorations of resilience and adaptive capacity explicit attention needs to be paid both to "resilience of what" and "resilience to what". We agree with this view while also recognizing that there are a complex and interrelated set of changes that are facing coastal communities. An important part of exploring adaptive capacity to change is to first understand the diverse array of changes that communities are undergoing and also the ones that community members perceive as most significant or most important to address. As Marshall et al. (2009) suggest, perception of risk is a key determinant of the willingness and ability to adapt.

As part of a multi-faceted research project focusing on marine conservation, climate change, and community adaptive capacity on the Andaman coast of Thailand, we used a community-based Photovoice process to explore the broader array of perceived changes both to the natural environment as well as to social aspects of several coastal communities. The broader project consisted of a series of interviews and surveys as well as the Photovoice process. The Photovoice aspect of the project had three purposes. First, it sought to understand how narratives and realities of environmental decline, change, and conservation relate to the particularities of people in different communities in a region. Second, the Photovoice portion of the project aimed, in part, to re-examine the idea that climate change is the only or most powerful change event re-shaping the combined social-ecological systems associated with the communities that we work alongside (e.g., Graybill 2011). In much recent work and research on problems related to conservation and development, climate change has become a dominant and overriding narrative. As argued by Swyngeduow (2011), climate change could be seen as the current objet petit a - a Jacques Lacan inspired term which refers to an object of focus (or of desire) that distracts us from having a holistic vision or understanding - of conservation and development-related work and research. Finally, using Photovoice, we aimed to create a comprehensive picture of the changes that the communities were facing. Moreover, neglecting to explore change in an open-ended fashion risks making ungrounded and faulty assumptions about the types, extents, and significance of the various changes that communities are experiencing, which may in turn lead to an examination of adaptive capacity that is overly focused on a narrow type of adaptation. Photovoice was the method chosen to achieve these purposes because we felt it would provide rich visual data focused on the experience of participants that could be shared both within and beyond the communities that we were working with (Harper 2003, Wang and Burris 1997, Castleden et al. 2008).

This paper explores the results of two community-based Photovoice processes that we undertook with several coastal communities on the Andaman coast of Thailand. Prior to exploring the results, we introduce the research sites, provide an overview of Photovoice and the modified process that we used, discuss our sampling strategies, and provide some descriptive statistics. In conclusion, this paper discusses the results in consideration of the aforementioned goals and prospects for future research on social and ecological change using Photovoice.

\section{Description of Site and Regional Changes}

This research project was done on the Andaman coast of Thailand - a region that has undergone significant social, economic, environmental, and climatic changes in recent decades. Extending more than $500 \mathrm{~km}$ from north to south, the Andaman Coast Bioregion of Thailand is considered to be an area of global geographic and ecological significance (World Heritage Nomination Document 2010). The confluence of ocean currents coming from the Bay of Bengal and the Indonesian through-flow via the Straights of Malacca results in an area of high biodiversity and endemism (World Heritage Nomination Document 2010). The region also contains significant areas of mangroves, coral reefs, and sea grass beds (Juntarashote 2005); however, all of these environmental assets are significantly degraded and under threat (World Bank 2006). Major challenges facing these critical habitats in the region include erosion, eutrophication, climate change, coastal development, pollution, overharvesting, and 
unsustainable fishing and tourism practices (Juntarashote 2005, Dearden, Bennett and Rollins, 2006, World Bank 2006, BOBLME 2010). Economically, communities across the region have shifted away from fishing and towards tourism and other livelihoods. Communities on the Andaman Coast of Thailand have been reliant on fishing and subsistence harvest for survival since time immemorial and fisheries are still central to the regional economy (Panjarat 2008). In 2001, across the six provinces of the Andaman Coast (Ranong, Phang-nga, Phuket, Krabi, Trang, and Satun) there were an estimated 621 fishing villages and 15,742 fishing households (Sielert and Sangchan 2001). In the last few decades, however, increased fishing pressure has led to sharp declines in fish stocks in the region (Panjarat 2008). Approximately 5.5 million tourists visit the region annually (DOT 2009). Besides fishing and tourism, development on the Andaman coast consists primarily of resource-based industries of mining, agriculture, rubber and oil palm plantations, logging, and aquaculture.

Another significant change for many of the traditional fishing villages on the Andaman coast of Thailand - that is partially a response to environmental degradation in the region - is the creation of an extensive network of marine protected areas (MPAs) that are under the jurisdication of the Department of National Parks in Thailand. In total, there are 18 MPAs on the Andaman Coast covering an area of more than 538,000 ha (World Heritage Nomination Document 2010). According to Prasertcharoensuk et al. (2010), these MPAs were created in a 'top-down fashion' with little local inclusion or support for designation and management. Though these areas were intended to be "no-take zones" for fishers, the governance and management of the marine portion of these areas has been critiqued as ineffective (Prasertcharoensuk et al. 2010) and monitoring and enforcement of regulations is almost non-existent (e.g., Lunn and Dearden 2006).

Climate change forecasts suggest that, by 2045-2065, climate change will result in increased maximum $\left(+3.19^{\circ} \mathrm{C}\right)$ and minimum temperatures $\left(+3.4^{\circ} \mathrm{C}\right)$, an $8 \%$ increase in precipitation, more warm days and less cool days, longer and warmer summers and shorter winters, and more intense rainfall during the rainy season (START 2010). Sea level is expected to continue to rise between 1-2 mm a year in the Indian Ocean (Unnikrishnan and Shankar 2007). However, a report on the Krabi province of the Andaman coast suggests that sea level could rise as much as $1.1 \mathrm{~cm} /$ year in the next 10 years and an average of $0.84 \mathrm{~cm} /$ year over the next 25 years which could result in shorelines retreating in the Krabi region between 10-35 metres/year (START and WWF 2010). Elevated oceanic temperatures associated with a warming climate have already resulted in coral bleaching events in 1992, 1998, and in 2010. The 2010 event was the most significant to date and resulted in high levels of bleaching and mortality across the region (Phongsuwan and PMBC 2011). Esser (2010) suggests that intensified rainfall events in the region will lead to increasing sedimentation and decreased salinity, which have implications for coral reefs, sea grass, and mangroves and related livelihoods. These climate-related trends are likely to continue in the foreseeable future.

Our photovoice research was conducted in two sites along the Andaman Coast of Thailand - 1) Baan Lions and Baan Tapae Yoi on Koh Phrathong situated on the outer coast of Phang-Nga province and 2) Baan Tha Khao on Koh Yao Noi located in Ao Phang-Nga (see Figure 1; Note: Baan = village; Koh = island; Ao = bay). These villages were chosen as study sites as they had a mixture of different livelihoods but still relied on the marine environment, were situated within the environs - inside or within 3 kilometers - of an MPA, and were located near a variety of different marine ecosystem types (i.e., corals, mangroves, seagrass). These criteria were used for selection of study sites because we were seeking insight into the experience of coastal communities, rather than generalizability to the entire coast as this would require a much larger sample. The sites selected for Photovoice were also selected from a larger sampling of 7 communities used in our broader study. According to the health center on Koh Phrathong, Baan Lions has a population of approximately 57 people who are primarily wage laborers and fishers. Baan Lions is an international NGO - i.e., Lions International - created posttsunami village that was built after another village on the island - Pak Jok - was demolished during the 2004 tsunami. When we were in the village only about 44 of the approximately 165 houses were 
inhabited. In Baan Tapae Yoi, the population of 119 consists mostly of fishers and wage labourers. The people in both Tapae Yoi and Baan Lions are of Thai-Chinese and Moken ancestry and are largely Buddhist. For infrastructure, Koh Phrathong has one health center, one school, and a Buddhist monastery. Both villages on Koh Phrathong are surrounded by significant areas of mangroves and seagrass and there are coral reefs located offshore (World Heritage Nomination Document 2010). There is a proposed national park - Koh Ra-Ko Phrathong National Park - on the island and in the marine area around the island that is strongly opposed by locals (World Heritage Nomination Document 2010). Health center statistics from Koh Yao Noi, a more populated island of approximately 5000 mostly Thai Muslim inhabitants with 7 villages, indicate that Baan Tha Khao has a population of 407 people who work primarily as daily wage labourers, in agriculture, and as fishers. The island has small areas of seagrass and mangroves and is situated near a number of coral reef-fringed islands that are largely situated within Than Bhok Khorani Marine National Park and Ao Phang-Nga Marine National Park (World Heritage Nomination Document 2010).

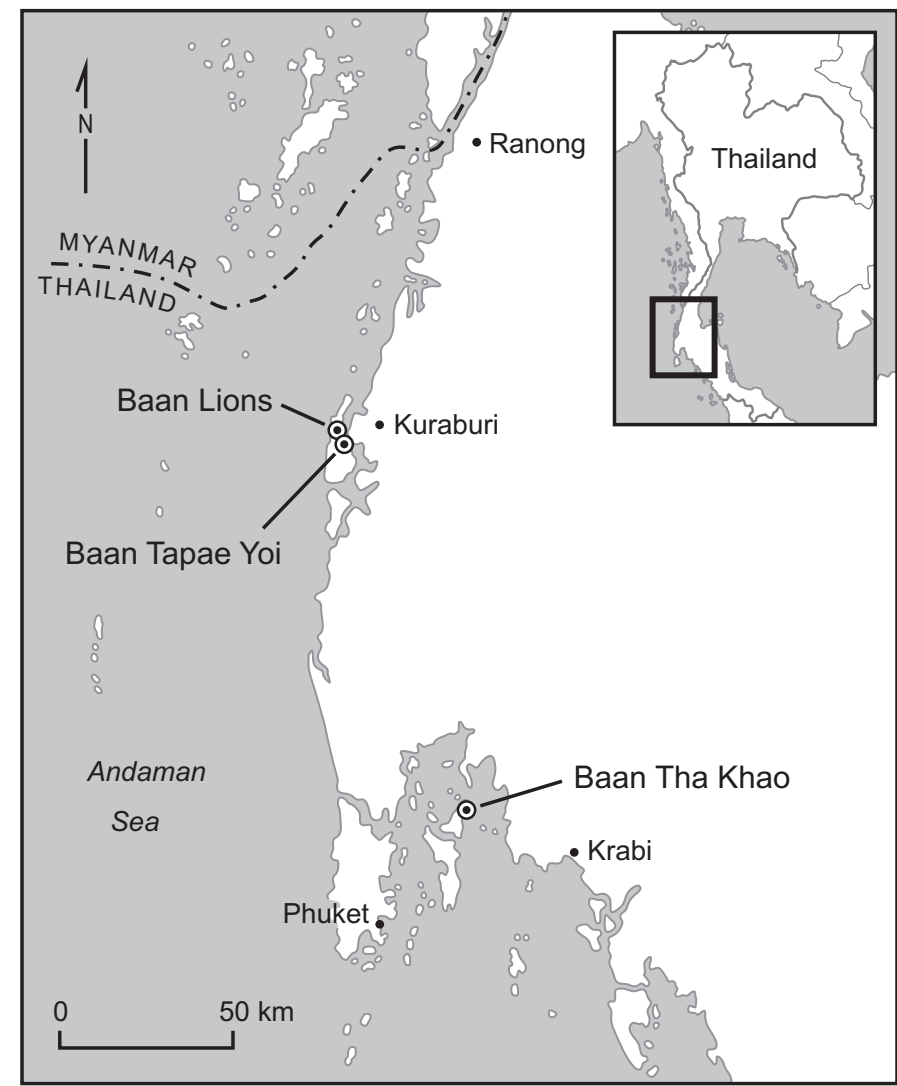

Figure 1 - Map of Photovoice Study Sites on the Andaman Coast of Thailand (Credit: Ole Heggen)

\section{The Photovoice Method}

Photovoice was used to research social and environmental change in the marine environment and selected coastal communities. Photovoice uses images of the community made by people themselves thus leading to shared understanding and ownership of the research process and outputs (Castleden et al. 2008). According to Wang and Burris (1997, p. 369), Photovoice is "a process by which people can identify, represent, and enhance their community through a specific photographic technique. It entrusts cameras to the hands of people to enable them to act as recorders, and potential catalysts for change, in their own communities". Photovoice originated in public health as a method of assessing health needs 
(Wang and Burris 1997) and has since been used in numerous settings and with various populations (see Hergenrather et al. 2009 for a review). The originators suggest that the goals of photovoice are threefold: “(1) to enable people to record and reflect their community's strengths and concerns; (2) to promote critical dialogue and knowledge about important community issues through large and small group discussions of photographs; and (3) to reach policymakers" (Wang and Burris 1997, p. 370). Photovoice has seen significant usage in health, education, psychology, and community development research; however, it is only recently emerging as a tool for examining changes in the natural environment or for exploring human environment-interactions. Several noteworthy examples include the following: Berbes-Blazquez (2012) used Photovoice to assess the relationship between ecosystem services and human wellbeing; Bosak (2008) used the process to examine conceptions of nature with communities in India; Baldwin and Chandler (2010) focused on community perceptions of climate change; and, Beh (2011) examines its usefulness for generating conservation knowledge in Kenya. A team from Lakehead University has also recently used Photovoice to explore climate change with an arctic aboriginal community in Canada (Lemelin et al. 2011). However, our research was the first study that we are aware of that focuses specifically on social and ecological change.

We utilized a modified Photovoice process that was based on the steps suggested by Castleden et al. (2008) and included six steps that are described below. First, participants were recruited and a Photovoice training workshop organized. During the workshop, we explained Photovoice, instructed participants on the use of cameras, and posed the central questions of the study. The questions posed were the following: 1) What changes do you see in the natural environment?; and 2) What changes do you see in your community? Secondly, the waterproof digital cameras (Note: we used Kodak's Easyshare Sport C123 Camera as they were low cost and waterproof) were given to the participants for two weeks to give them time to take photographs. We checked in periodically with participants by phone and after the first week visited participants to download the first batch of photographs, remedy any technical issues, and discuss progress. After two weeks, we collected the cameras and downloaded the photographs for printing. Third, after printing the photographs, in-depth semi-structured interviews were undertaken with participants to explore changes portrayed in selected photographs and to learn the narratives behind the photographs. Interviews were done in translation from Thai to English. Fourth, analysis of results was done through initial participatory exploration (coding, if you will) of the changes shown in photographs and explained in each interview with each participant and then subsequent discussion of the main topics of the interviews (Wang and Burris 1997, Gotschi, Delve and Freyer 2009). The topics discussed by all participants were grouped into main themes for each Photovoice processes. A final layer of qualitative analysis was done by the principal author during the writing of this paper to search for underlying or hidden themes. Fifth, books in Thai and English were produced for and with participants from each Photovoice process through presenting photographs that participants selected and excerpts from the narratives gained during the interviews. The results and translations presented in the book were verified and edited with participants and they were asked to ensure that their voices were accurately represented. Books were produced for all participants, village chiefs, and local schools (Bennett and Dearden 2012a, 2012b). Finally, in one of the communities a workshop was held to discuss the outcomes and the implications of the Photovoice process. Our intention was to hold a workshop in the second community but our visit was ill-timed - dry season meant that everyone was working hard in fisheries, tourism, and agriculture to make money - so we were only able to meet with participants individually. As such, the substantive results presented herein are based primarily on the photographs and interviews with individual participants and do not include workshop discussions. 


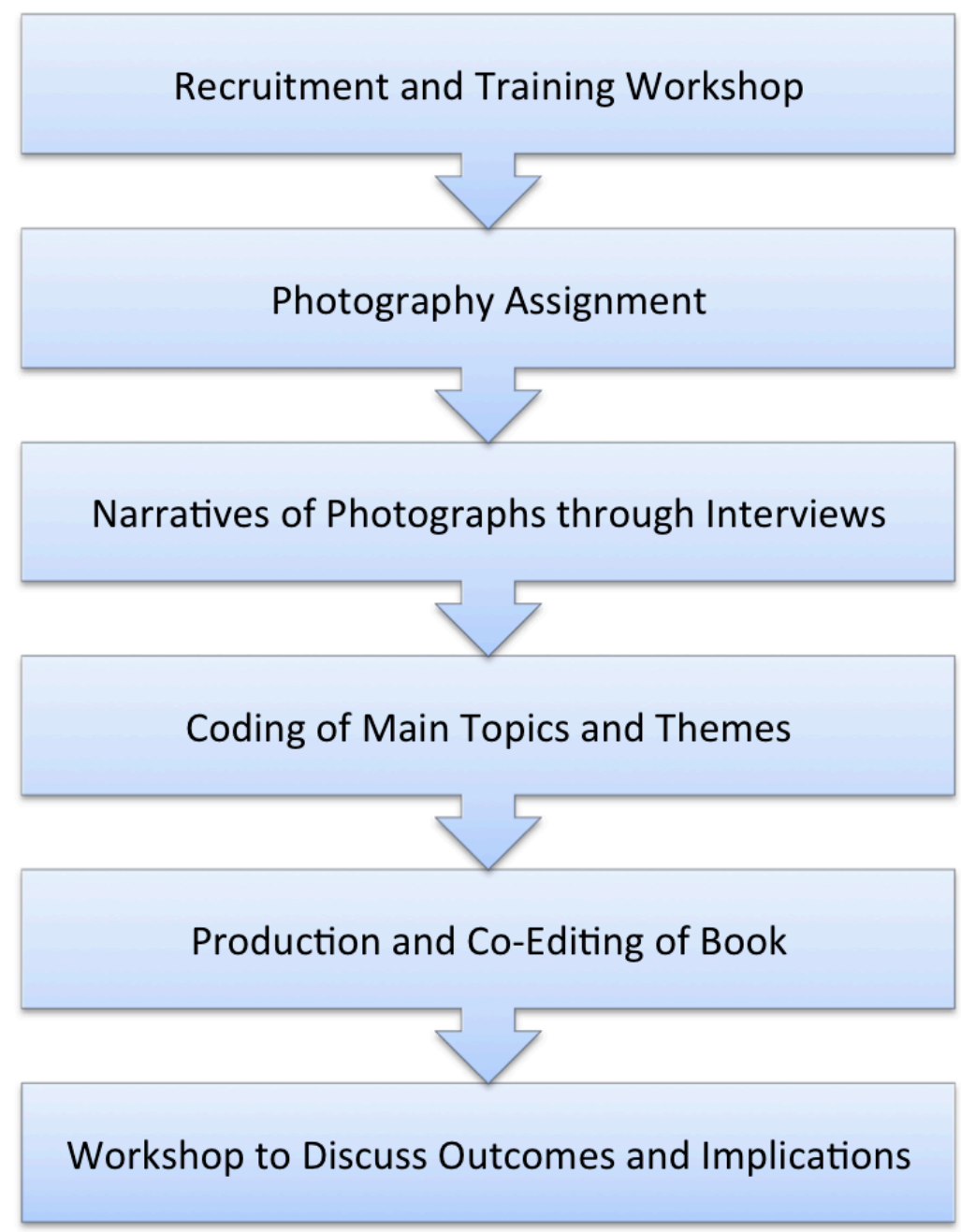

Figure 2 - The modified Photovoice process (after Wang and Burris 1997, Castleden et al. 2008)

\section{Sampling, Selection, and Descriptive Statistics}

Two research sites were chosen for the Photovoice process to represent varying livelihood mixtures, different MPA models, and different ecosystems. These villages are described in an earlier section of this article. We had originally intended to conduct a third Photovoice process in another village - one that was solely dependent on fisheries - but time constraints did not allow for this. The photovoice process was conducted with 9 individuals on Koh Phrathong - 4 from Baan Lions and 5 from Tapae Yoi - and 11 individuals in Baan Tha Khao. We used a combination of snowball and purposive sampling to select individuals who were both a) knowledgeable about the marine environment, and b) representative of various genders, socio-economic groups, ethnicities, and livelihood groups. Snowball sampling is a process whereby an initial contact or community gate-keeper suggest possible participants who in turn make recommendations of additional respondents (Neuman 2000). Purposive sampling allows for the selection of individuals to represent certain groups or who are knowledgeable on the topics under study and is suitable for an exploratory study such as this (Neuman 2000).

On Koh Phrathong, 5 females and 5 males were originally selected to participate but one of the males dropped out part way through the process (due to a temporary relocation for work) and in one case a husband participated with his wife. In Baan Thao Khao, 7 males and 4 females were initially selected 
to participate; however, in two of the cases husbands opted to take pictures and do the interviews alongside their wives. Participant ages ranged between 20-60+ years of age on Koh Phrathong but the majority of participants were between 40-60 years of age in Baan Tha Khao. The generally higher age of the participants in Baan Tha Khao is related to declines in fish and fisheries-based livelihoods and the out migration of youth. Livelihoods of participants ranged from solely fishing, to marine-based tourism, to a mixed portfolio of livelihoods. Participants took between 16 and 176 photographs. The length of the interview ranged between 26 minutes and 4 hours and 27 minutes. Several of the longer interviews took place over several sessions.

Before proceeding with our discussion, we want to recognize the limitations of our process which include our limited sample sizes in both communities, the time of year when the research happened (rainy season), and the limited timeframe spent on this aspect of the research. Though more than a month was spent conducting the research in each community and an additional month was spent doing transcription, analysis, and editing the book for each community, this still felt like a limited amount of time. The results presented here are illustrative and not representative due to the purposive and snowball sampling methods used. Finally, a significant limitation of our application of the Photovoice method is related to, in one case, only a brief concluding workshop and, in the other case, no concluding workshop. Previously recognized challenges and limitations of the Photovoice method include length of the process, participant retention, and seasonality and weather (Castleden et al. 2008). There can also be challenges associated with portraying intangibles as there are limits to what is observable (Rose 1993, Castleden et al. 2008). Just as Photovoice can facilitate learning and action, various factors including class, race, age, and gender can influence what pictures are taken (Prins, 2010).

\section{Results}

This following section of this paper explores the results of the Photovoice process in three sections: 1) environmental change, 2) social changes, and 3) underlying themes.

\section{Environmental Change}

Photographs taken by participants explored a number of themes related to changes in both the marine and terrestrial environment. The changes can be seen as trends, and overviews from both sites are presented in Table 1. There were a number of similarities between the sites. In both sites, environment oriented photographs and narratives focused on declines in fish and other marine species (Figure 3a), increases in erosion on the islands, the impacts of tourism development on nature, and the conservation areas created by the communities. One participant noted how "In the past, I got 100 kilograms of silago per day with no nets. Now it takes more than 10 days to get that many. Now, it is around 10-20 fishes a day. I get a maximum of 10 kilograms." (Figure 3b). Some participants suggested that the declines were because "Lots of people make a living [from fishing]. There are more humans than fish" and several others blamed the change on commercial boats coming into the area or the use of destructive fishing gears.

\begin{tabular}{|l|l|}
\hline \multicolumn{1}{|c|}{ Site A - Baan Lions and Tapae Yoi } & \multicolumn{1}{c|}{ Site B - Baan Tha Khao } \\
\hline - Declining fish and other species & - Decreasing fish \\
- Changes in the island forest after the tsunami & - Increasing erosion \\
- Increasing erosion around the island & - No time for nature to recover \\
- Erosion in front of community from removing mangroves & - Impacts of tourism on nature \\
- Shifts in species composition and arrival of new species & - Less damaging fishing gear \\
- The seagrass areas are more patchy & - Artificial reefs in the ocean \\
- Increasing mangroves and related resources & - More garbage \\
- Changes in rainy and dry season & - Disappearing species of fish \\
\hline
\end{tabular}


- More storms

- Marine species are dying from too much freshwater

- Increasing algal blooms and coral bleaching

- More development will cause nature to decline

- Island deer are increasing
- Dead coral on the beach

- Less big fish

- Community is doing conservation

\section{Table 1 - Environmental changes portrayed during the Photovoice process}

A number of different themes also emerged from the two Photovoice processes. In Baan Tha Khao, photographs also concentrated on increases in garbage in the ocean and on land (Figure 3c), the negative impacts of artificial reefs in the ocean on fishing gear, the environmental benefits of switching to less damaging fishing gears, and dead coral washing up on the beach. Participants in Baan Tha Khao also explored not only declines in the number of fish but also how there were "less big fish" and how many species of fish were disappearing or going extinct. For example, one participant said "These are big fish. We used to get 20 for a boat. Now we only get 3 of that size." while exploring a picture that he had taken (see Figure 3d). One participant discussed how different species of grouper were disappearing as a result of being targeted for aquaculture and food: "Species of fish do disappear. I am almost 50 and I have seen this change clearly. There are many species in the grouper family and some of them have disappeared....Fish have no time to reproduce....The small ones are sold to aquaculture. The big ones are sold to middlemen...Groupers are a species that do not migrate." Another participant explored how they don't catch as many of certain species and how some species might be facing extinction: "Some of them we do not catch so much anymore - for example, the "Japanese fish" (i.e. redbelly yellowtail fusilier) and the "goat fish" (i.e. cory catfish). There also used to be more varieties of different fishes. You cannot count them all. Many of them have decreased, including brown marbled grouper, red mouth grouper, goldband fusilier, and whipfin majora." Later in reference to another picture, the participant stated "There used to be lots of them. It raises fears that it might be going extinct."

In Baan Lions and Baan Tapae Yoi, participants explored changes in the density of seagrass bed, post-tsunami impacts on the island's forest, the increased density and abundance of mangrove forests in the area due to the ending of charcoal concessions (Figure 3e) and how this had resulted in increases in marine resources from mangrove ecosystems (e.g., certain species of crabs, oysters, and fish), increases in the number of deer on the island, the arrival of new species in the area, and shifts in the number of certain species relevant to before. For example, one participant showed how one species of starfish was increasing in number (Figure $3 \mathrm{f}$ ) and also how a new species of sponge started growing in the seagrass meadows after the tsunami. In Baan Lions and Baan Tapae Yoi, there were also a number of climate related changes that were mentioned including changes in rainy and dry season, more storms, increasing algal blooms and coral bleaching, and dying species in the mangroves from too much freshwater. There was only one mention of each of these climate-related themes whereas most of the other themes had multiple mentions. Erosion, an often mentioned change, might also be related to climate change and sea level rise. 


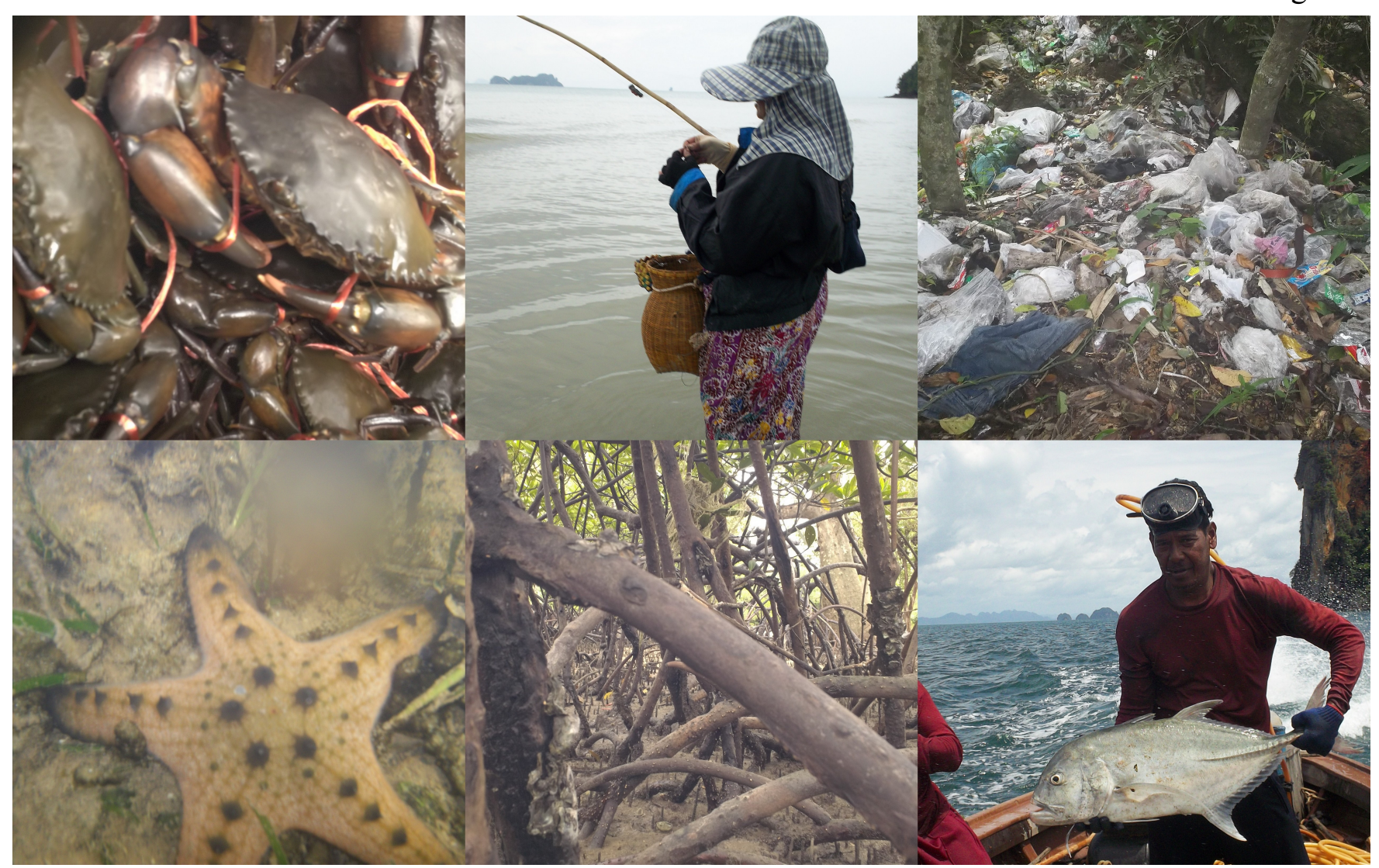

Figure 3 - Pictures portraying ecological changes in the marine environment taken by Photovoice participants. Moving clockwise from the top left corner - a) There are less marine resources, $b$ ) In the past there were lots of fish, c) The community is not prepared for garbage, d) There are less big fish, e) If the mangroves survive then the community survives, and f) An increasing number of this seastar,

\section{Social Change}

An overview of the social changes that emerged from the Photovoice process is presented in Table 2. A number of consistent themes related to social change emerged across the two research sites, including declines in fishing livelihoods (Figure 4a), increasing participation in tourism and rubber plantations, the presence of supplementary livelihood workshops (particularly for women) in the communities, increasing conveniences and technologies for doing livelihoods, and the impacts of migration and population growth. The actual or potential impacts of the existing or proposed national parks on fishing and harvesting were also discussed by participants in both sites. For example, in Baan Tha Khao one participant showed us a picture (Figure $4 \mathrm{~b}$ ) and explained "To make a living from the sea, it is not as flowing as it was before. The national park does not allow people to make a living from the sea. On the island, they don't allow people to enter to collect shells.... They want to protect it for when the tourists come." However, there were more differences than similarities between the communities on themes related to social change.

\begin{tabular}{|l|l|}
\hline \multicolumn{1}{|c|}{ Site A - Baan Lions and Tapae Yoi } & \multicolumn{1}{c|}{ Site B - Baan Tha Khao } \\
\hline - Shifting to different types of fishing and declining fishing & - Declining fishing livelihoods \\
- livelihoods & - Increasing rubber plantations \\
- Supplementary livelihoods programs and workshops & - Declining civic engagement \\
- Declines in traditional practices and knowledge & - Creation of the national park \\
- No more tin mining or charcoal concessions & - Increasing tourism impacts \\
\hline
\end{tabular}


A Picture of Change 10

- Increasing tourism development and livelihoods

- Outmigration of locals and in-migration of Burmese

- Possible creation of a national park

- More sharing and unity

- People continue to live simply and from the sea

- The change from Pak Jok to Ban Lions after the tsunami

- Discovering new uses for plants and species

- People come to the island to collect plants and animals

- New infrastructure was built after the tsunami

- Communities are trying to conserve natural resources

- More convenient ways to travel

- Expansion of plantations on the island
- More people moving into the area

- More infrastructure

- Changing fishing gears

- Market prices for fish have increased

- More engagement with market economy

- Youth are more educated and moving away

- More commercial fishing boats

- Land is being sold to outsiders

- Changing governance structures

- Muslim traditions are unchanging

- New technologies and conveniences

\section{Table 2 - Social changes portrayed during the Photovoice process}

In Baan Lions and Baan Tapae Yoi, photographs taken by participants also focused on shifts to different types of fishing, the loss of previous developments - tin mining and charcoal concessions - in the area, declining participation in aquaculture in the community, and declines in traditional practices and knowledge. Two areas where there were declines in traditional knowledge and practices were regarding to finding seafood to harvest and making shrimp paste. One participant explained about her photograph (Figure 4c): "I wanted to show how to look for conch. This is the trace of a dog conch. This is where the mouth comes out. Some people only look for the exposed ones...The new generation does not know how to look for traces like this." Another participant used a series of photographs (Figure 4d) to show the way that shrimp paste was made explicating that before "almost every household would [make shrimp paste]. It is a short-term livelihood but good income. Now, there are less people doing it because there are less krill and shrimp and many people don't know how to do it. The main reason is the loss of methodology." Several post-tsunami changes that were photographed and discussed in Baan Lions and Baan Tapae Yoi included the change from one village to the other, the new infrastructure that came with post-tsunami re-building programs, and the out-migration of local people to post-tsunami villages on the mainland. Several participants also noted the impacts of the post-tsunami funding and developments on levels of social conflict and social life in the community. For example, one participant noted about life in the post-tsunami community of Ban Lions (Figure 4e): "The Lion Foundation built the village and named the village after the foundation. It is good that they built the houses. But there are not enough people for the houses. They are close together and noisy....Life is framed differently in Baan Lions. It is like a gated community in Bangkok. In the old village, you had houses near the sea and when you walk along there are houses along the way." According to one participant, the social conflict was related to corruption due to the influx of financial capital into the region for development projects but since the "corrupt money" had disappeared there was "more unity in the community" (Figure 4f). Participants also expressed concerns about the negative environmental impacts that would come with increasing tourism development in the area.

Through the Photovoice process participants in Baan Tha Khao noted declines in civic participation, changes in regional governance structures, and the impact of tourism on social norms in the community. One participant who drove boats for tourists used a distant photograph of women in bikinis on a beach (Figure 4g) to explain how it impacts on Muslim culture: "Tourism is a change from the past. It is true that having lots of visitors brings work for villagers....A change is the naked Farang [foreigner]. Thai people tend to follow the trend. People on this island, the culture, trends to become like [foreigner] culture. This is a subject that is worrying, don't you think? People have started to dress like the Farang [foreigner], teenagers. Most people on this island are Muslim. Muslim people pray on Fridays. For tour guides, they don't get to go to the mosque on Friday." A number of participants also commented on the social changes - including less sharing in the community - associated with increasing engagement in the 
market economy resulting from: a) new and different livelihoods that relied directly on the economy (e.g., tourism), b) increased costs of living combined with more material desires, c) increases in prices that you can sell fish, and d) declines in fish catches. One participant commented about his photo (Figure 4h) that "There are more expenses. Everything has to be bought....It all requires money. So instead of sharing [fish], people sell it." Another photograph was used to show how "Before, you would collect shells and just give them away to your friends. But now, everything has a price." Participants also expressed their concerns about the permanent outmigration of youth who were going elsewhere to get educated and also and outsiders coming into the area to buy land. Despite all of the other changes, one participant showed a picture of a Muslim ceremony and commented that Muslim traditions were strong and unchanging in the community (Figure 4i).

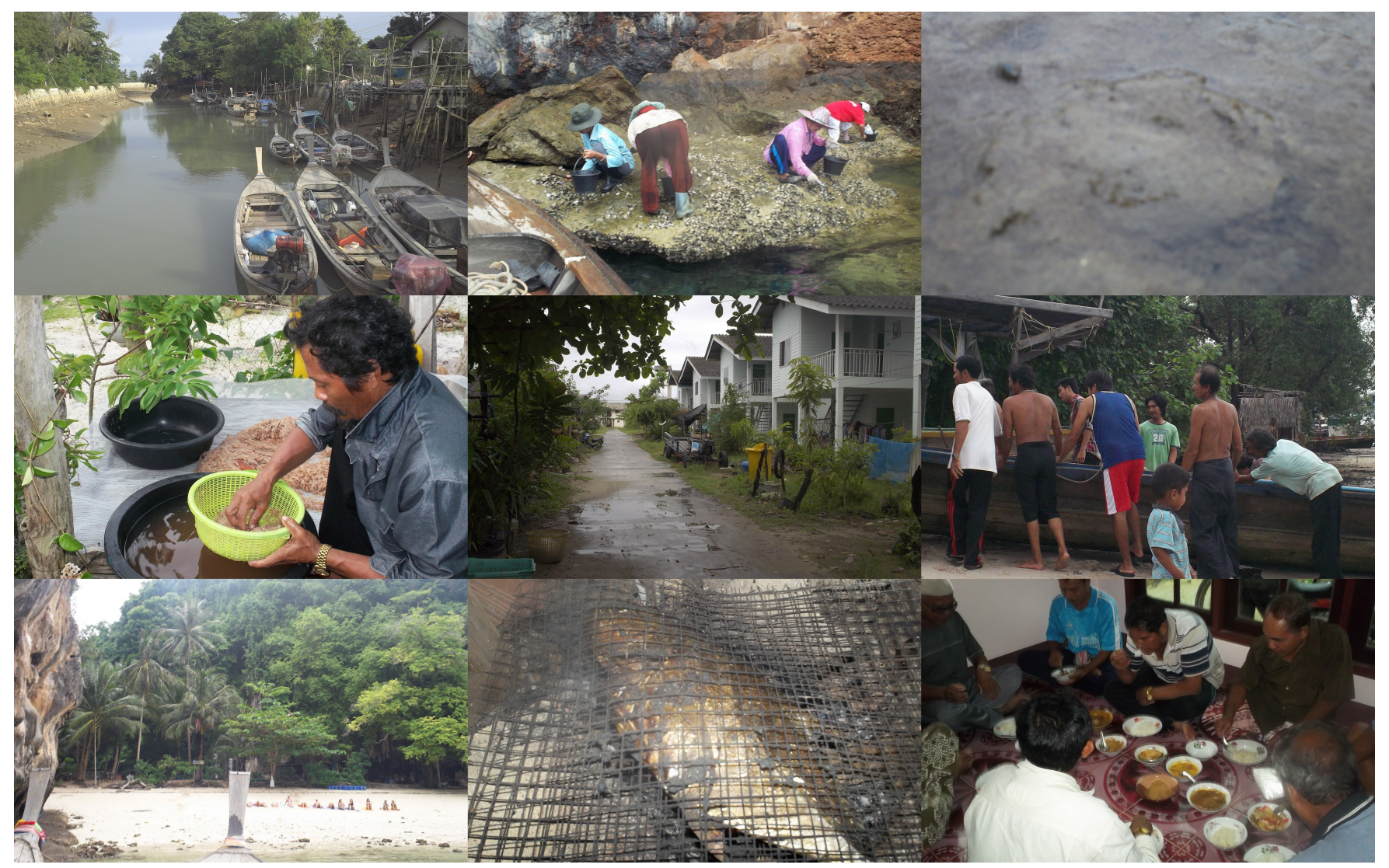

Figure 4 - Pictures portraying social changes in the communities taken by participants. From left to right - Top row: a) There are less fishing boats in the canal, b) National parks does not allow collecting, c) The trail of a dog conch, Middle row: d) Less people make shrimp paste now, e) Life is framed differently in Baan Lions, f) More unity in the community, Bottom row: $g$ ) The impacts of tourism, $h$ ) Everything has to be bought, and i) Muslim traditions will not change.

\section{Underlying Themes}

There were also a number of significant underlying themes that emerged during the participants' descriptions of their photographs including: 1) the impact of ecological changes on social changes and vice versa, 2) the impact of macro-scale processes on local outcomes, 3) the powerlessness felt by local people to address some changes, 4) a sense of hopelessness and sorrow at the loss of fish and fisheries livelihoods, and 5) discussions of resistance to, and adaptation to, changes through local actions.

The impacts of environmental or ecological change can also be felt in the social sphere of the community's life and vice versa - a number of these "socio-ecological" changes were described during 
the Photovoice process. First, participants showed and discussed how a number of environmental changes led to social changes within the community and beyond. In Baan Tha Khao, participants felt that declines in fish had led to rises in the prices of fish, fewer livelihoods in fisheries, and declines in sharing within the community. On Koh Phrathong, lower abundance of shrimp and krill was said to have resulted in declines in the number of people doing traditional practices such as making shrimp paste. On Koh Yao Noi, declining fisheries was resulting in less time for fishermen to stop and have lunch together at sea as they needed to rush home and do other livelihoods in the afternoon (Figure 5a). Both smaller and less abundant conch, sea cucumbers, and other subsistence seafood was noted as a rationale for the communities to create small no-take zones in seagrass meadows on Koh Phrathong and no cutting zones in mangrove forests on Koh Yao Noi. Increasing numbers of mangroves were seen to be resulting in higher abundance of harvestable species in mangrove areas, which had a positive impact on the communities on Koh Phrathong. One participant in Baan Lions discussed how more numerous storm events and changes in the rainy and dry season had negative impacts on the livelihoods of fishers, both on the number of days that fishers were able to fish and on the amount of gear that was lost.

Second, social changes were seen to have environmental implications. For example, increases in the amount of tourism and in conveniences and technology were both discussed as resulting in increased amounts of garbage. Declines in fish and fisheries were attributed to changes in the number and efficiency of gears used by fishers, overall increases in the numbers of fishers which did not allow time for stocks to recover, and the number of commercial fishing vessels that were fishing illegally in inshore waters and zones reserved for small-scale fishers (Figure 5b). Some socio-ecological changes were discussed as being cyclical. For example, declines in fish resulted in increasing prices while increasing prices stemmed from more fishing pressure and declines in fish. There were also complex flows of causality across social and environmental spheres that were discussed by participants. For example, one participant on Koh Yao Noi discussed how declines in fisheries had resulted in a greater need to do agriculture and plantations and that this was leading to the destruction of island forests.

An important underlying theme was the uncontrollable impact of macro-scale processes - such as population growth, migration, economics, development, and governance - on local outcomes. For example, the impact of a) population growth at a regional level (e.g., in Ko Yao Noi island communities and in villages within Ao Phang-Nga Bay) and of b) centralization of fishing efforts in, and migration of fishers towards, larger regional centers (e.g., Phuket and Krabi) on fishing pressure and the abundance of marine resources was noted by a number of participants. For example, many participants in both sites made statements such as "There are more humans than fish.", "The sea is never without fishers.", "People come from both sides to collect", and "People come from all over." This was seen as partially to blame for declines in fishing livelihoods within the communities. The impact of macro-economics and market prices beyond the community also impacted on both the price at which people could buy items necessary for livelihoods and the price at which people could sell their products. Participants commented that the price of nets had risen significantly. The price of buying feed - in the form of nonmarketable fish from fishing piers - for doing cage aquaculture had also risen, participants on Koh Phrathong felt, because there were more cage aquaculture farmers and thus more demand for feed. It may be that this was also related to smaller fish becoming more economically valuable for other purposes. Market prices for selling rubber and fish were also constantly changing and having large positive or negative impacts on household incomes. Participants did not understand why and how market prices could change so drastically. The creation and management of national parks was discussed as an example of how governance decisions were made beyond the community and that the community did not have any input or control over these decisions. Cross-scale interactions that flowed in the opposite direction - i.e., from the local scale to higher levels - were not mentioned by participants. There were no photos or discussions of how changes at the community level influenced regional or national social or environmental outcomes. 
There were several emotive and active responses to the changes that were happening that were discussed by participants of both Photovoice processes that emerged during analysis. First, there was a feeling of powerlessness and hopelessness associated with the aforementioned macro-scale processes and also environmental changes and fisheries declines. Many participants felt that nothing could be done about declines in the numbers of fish because of several factors, including a) the numbers of fishers and level of fishing pressure, b) lack of adherence to rules and increasing numbers of commercial boats coming into restricted areas, c) the inability of communities to make rules for their fisheries because it remained an open access resource, and d) the lack of capacity of local fisheries officers to enforce rules. Participants also explored how they felt powerless about the increasing number of areas that they could not access or use for livelihoods purposes, including the area contained in the national park and areas purchased by outside religious groups and business people or investors for tourism development or agriculture. As one participant comments: "It is a shame that pieces of land are in the hands of outside businessmen. In Baan Tha Khao, about $40 \%$ of the land does not belong to locals....It is a big change from having land to renting houses. For some people, it is probably necessary to do so. But I think it is better to keep the land to make a living for the next generation."

Second, there was a sense of sorrow or mourning associated with the social or community changes associated with fisheries declines. This emotion was apparent in narratives about the loss of fisheriesbased livelihoods (Figure 5c), decreases in the number of fishing boats in the community, changes in traditional social structures in the community, loss of traditional knowledge, the lack of participation of youth in fisheries, and the outmigration of youth to get educated.

Finally, participants explored some active changes that represented local adaptations or resistance to the other changes that were happening. As fisheries declined and household expenditures increased, participants explored how people were adapting through engaging in alternative livelihoods such as tourism and desert making (Figure 5d) and also through doing activities associated with the King of Thailand's concept of a "sufficiency economy" such as raising livestock and making gardens (Figure 5e). One participant suggested that to address the increased cost of living people have to "adapt themselves according to the changes that happen" through working harder but also through curbing spending, sharing more, and living within one's means. In both communities, participants discussed the creation of small conservation areas as means of resisting declines in marine species and outside encroachment into the area. Results also revealed that for a number of participants there was a sense that activities such as "continuing to live simply" (Figure 5f) and maintaining Muslim traditions (Figure 4i) were means of resisting the disruptive power of unwanted social change. All of the means of addressing change through adaptation or resistance that participants mentioned were local-scale or community-based solutions that often did not match the scale of the change that they were addressing. 
A Picture of Change 14

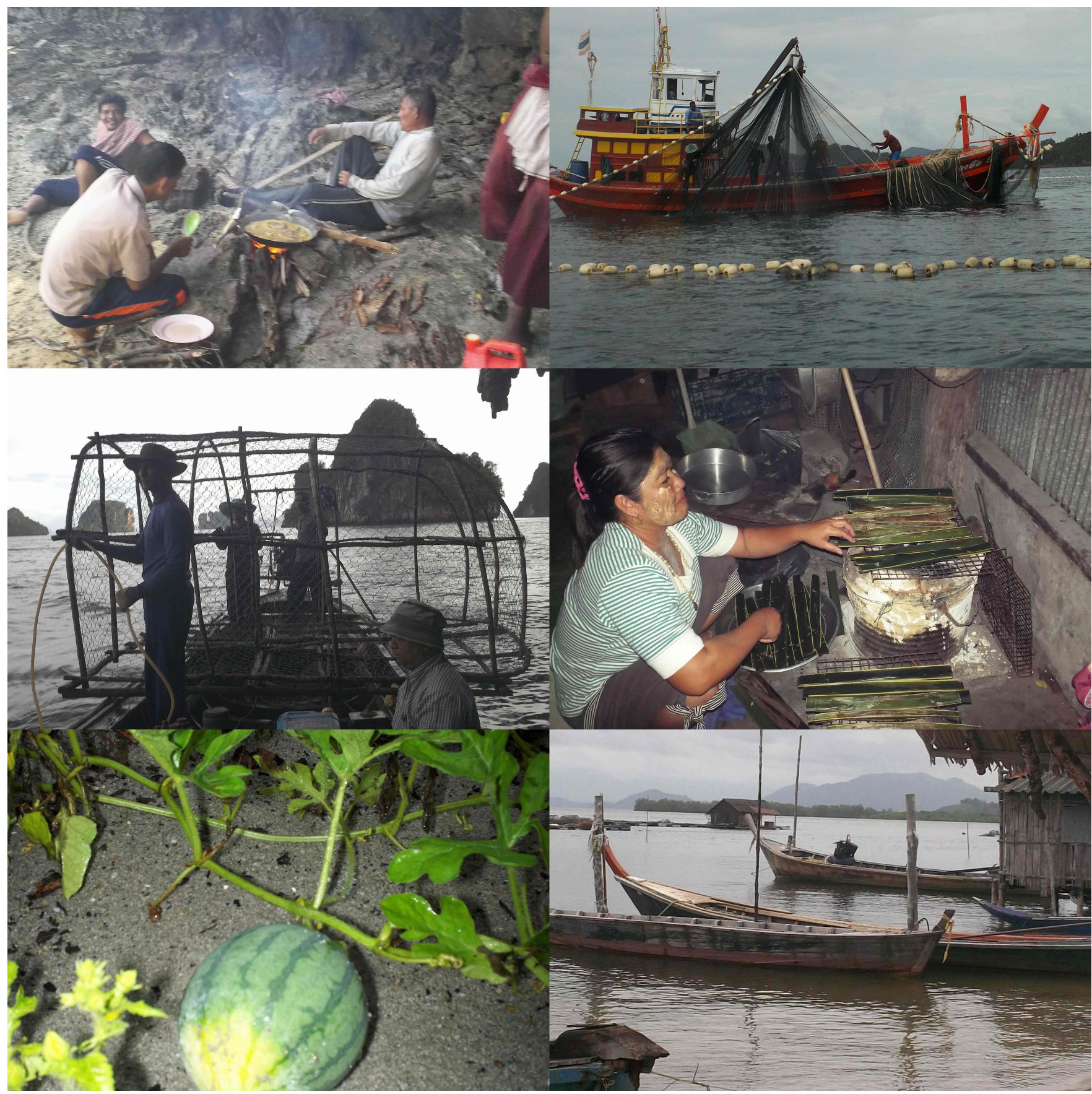

Figure 5 - Pictures portraying underlying themes of socio-ecological change, macro-scale processes, powerlessness, sorrow, and local-scale responses to change. From left to right. - Top row: a) Traditional way the fishers would eat lunch, b) Many anchovy boats come in; Middle row: c) Many fish are declining or disappearing, d) Making deserts to sell; Bottom row: e) The King's sufficiency gardens, f) Continuing to live simply.

\section{Discussion and Conclusion}

This article presented the results of a community-based Photovoice project conducted on the Andaman coast of Thailand. Our goals were to explore the broader array of changes that were facing communities, to understand how environmental change and decline were impacting on communities in the region, and to re-examine the centrality of climate change within a research project focusing on adaptive capacity. This concluding section discusses the results in light of these goals, and the prospects 
of the Photovoice method for future research and applied projects in the area of conservation and/or development.

First, Photovoice was a useful process for understanding the broader array of changes that were facing the communities. The environmental results from the Photovoice process were largely confirmatory of what we already know from scientific studies about environmental change and decline in the region. For example, we already know that fishing capacity is too high and that fish are in decline in the region (e.g., Panjarat 2008). This demonstrates that Photovoice can provide an important form of triangulation for scientific and quantitative studies. More interesting perhaps are the ecological specifics that emerged from the Photovoice process, such as the near extinction or disappearance of specific species in Ao Phang-Nga, the declines in groupers from aquaculture in Ao Phang-Nga, the increases in certain species of starfish in the seagrass meadow on Koh Phrathong, and the appearance of new species after the tsunami on Koh Phrathong.

The social results often focused on changes that were particular to that one community - such as the way that life has changed in Baan Lions or how there is "less time to sit and talk" in Baan Tha Khao. However, some generalizable themes related to changes that were happening in all of the communities were also discussed, including changes in livelihoods, impacts of the national park, and effects of declines in fisheries. Moreover, we felt that the Photovoice method was a good way to explore the complexities of environmental change, the particularities of social change, and the intricate interplay between all of the changes that are happening within communities and regionally. Often at the end of the Photovoice interview, participants would tell us that it was better to talk about change through taking photographs and then using the photographs as a point of reference for discussion than just through talking about change. Participants commented "Like this you [the interviewer] can see it too." and "Now I know more about the changes that are happening." Throughout our broader research project, we also used in-depth interviews to explore the question of social and ecological change with people. Answers during the interviews were often quite short and participants might only provide one or two examples. The results of the Photovoice process were much richer, more varied, and more in-depth.

Second, Photovoice was a good way to examine the interaction between environmental change and decline and the social sphere of communities. As discussed previously, participants often discussed how fisheries declines changed livelihoods, prices of fish, and the social institutions in the community. The implications of degraded ecosystems and habitats were also discussed. For example, pictures were taken that showed the declining density of seagrass and participants explained how this had a negative impact on conch and sea cucumber and how this made it harder for the community to find seafood to harvest. Similarly, mangroves were shown to be important for erosion control and as a source of food as one participant noted: "If the mangroves survive, the community survives." Coral reefs were also mentioned important habitats for fish and as places for tourists but no participants took pictures of coral reefs even though they were given underwater cameras. This could have been partly because of the further distance required to travel to the coral reefs or because the cameras only had a maximum depth of 9 feet.

Third, potential environmental impacts arising from climate change did not feature significantly in results emerging from the Photovoice process. Many participants did mention increased erosion in both communities although this was often attributed to local removal of trees or the tsunami. One participant on Koh Phrathong discussed increases in storms and changes in rainy and dry season. Another participant mentioned increases in algae and the impact of this on coral reefs. Yet, overall, the limited amount of discussion given to climate change emerging from the Photovoice process was surprising to us. Interviews and surveys were also conducted in the same communities. Many climate change impacts, particularly storm events, erosion, and changes in seasons, were discussed by participants in interviews. These same three climate-related changes were also ranked highly in surveys (unpublished data). Why these changes did not get as much attention during the Photovoice process could be attributed to the difficulty of photographing these concepts or to the ideological distance of 
these changes from everyday life. Or, perhaps, climate-related changes are simply not as central to people's qualitative narratives of their environment and their communities in this context.

In conclusion, our research suggests that Photovoice is a powerful method for examining social and environmental change and that results emerging from the process are useful inputs into community dialogues about natural resource management, conservation initiatives, and community adaptive capacity and development. The communities with whom we worked felt that the process was valuable, trusted in the legitimacy of the ideas and knowledge portrayed, and were satisfied with the outcomes. Participants in Baan Thao Khao said that they wanted to do "more of this type of research." However, we want to recognize that, as with most methods, it is preferable to combine Photovoice with other methods to get a more complete picture. Photovoice is also likely to be more effective as a catalyst of change if it is done over a longer timeframe and in an iterative manner as suggested by Castleden et al. (2008). In our research, a more effective concluding workshop that explored ways of addressing unwanted changes would likely have added to the power of the Photovoice process. Yet, the Photovoice books produced with the communities (Bennett and Dearden 2012a, 2012b) also fulfilled part of the role of these workshops through consolidating the knowledge gained from the process and creating shared understandings (Baldwin and Chandler 2010, Baldwin et al. 2012). We also want to recognize that in real-world, community-based and participatory research, prescribed multi-stage processes such as Photovoice should not limit our reflectivity and flexibility because "it is ethical and logical to consult with research subjects and adapt to situations arising in the course of the research" (Sadoway 2002 p 35). Books - rather than workshops - were chosen by the participants as an output. Perhaps the most effective and constructive way to use Photovoice would be as part of long-term ongoing conservation, development, or climate change adaptation projects by organizations that are deeply involved with, and committed to, a community so that results and outputs will have immediate and enduring utility for communities and practitioners. Academic researchers are thus likely to be the most useful to communities if they integrate into local community-based organizations and non-governmental organizations when conducting Photovoice.

\section{Acknowledgements:}

The results presented in this article are one aspect of the work of Project IMPAACT (http://projectimpaact.asia) - a project of the Marine Protected Areas Research Group, Department of Geography, University of Victoria, Canada. Financial support for this project came from the Social Science and Human Research Council of Canada and the Bay of Bengal Large Marine Ecosystem Project. The principle author of this article is sponsored by a Trudeau Scholarship and a SSHRC Joseph Armand Bombardier Canada Graduate Scholarship. We would also like to recognize our Thai partners the Department of National Parks, Niphon Phongsuwan of Phuket Marine Biological Centre, and researchers at Prince of Songkla University - and the invaluable contribution of two research assistants Piyapat Nakornchai (Por) and Alin Kadfak. A special thank you goes to the community participants who engaged with us in undertaking the Photovoice processes described herein. The map was created by Ole Heggen at the University of Victoria.

\section{References}

Baldwin, C. and Chandler, L., 2010. "At the water's edge": Community voices on climate change. Local Environment: The International Journal of Justice and Sustainability, 15 (7), 637-649.

Baldwin, C., Osborne, C., and Smith, P., 2012. Infill Development for Older Australians in South East Queensland; An Analysis of the Preferences of Older Australians in an Urban Environment. Report 
published by the University of the Sunshine Coast. p. 109. Available from www.usc.edu.au/seniorliving [Accessed on 10 September 2012].

Beh, A., 2011. Do you see what I see? Photovoice, community-based research, and conservation education in Samburu, Kenya. Dissertation (PhD). Colorado State University.

Bennett, N., and Dearden, P., 2012a. A History of Change: An Exploration of Environmental and Social Change in Ban Tha Khao. Report for Project IMPAACT, Marine Protected Areas Research Group, University of Victoria. p. 82. Available from:

http://issuu.com/mrnathanbennett/docs/a_history_of_change_-_bennett_and_dearden [Accessed on 10 September 2012].

Bennett, N., and Dearden, P., 2012b A Picture of Koh Phrathong: An Exploration of Change on the Andaman Coast of Thailand. Report for Project IMPAACT, Marine Protected Areas Research Group, University of Victoria. p. 72. Available from:

http://issuu.com/mrnathanbennett/docs/a_picture_of_change_on_koh_phrathong_-_bennett_and [Accessed on 10 September 2012].

Berbés-Blázquez, M., 2012. A participatory assessment of ecosystem services and human wellbeing in rural Costa Rica using Photo-Voice. Environmental Management, 49 (4), 862-875.

Bosak, K., 2008. Nature, conflict and biodiversity conservation in the Nanda Devi Biosphere Reserve. Conservation and Society, 6 (3), 211-224.

BOBLME, 2010. Transboundary Diagnostic Analysis - Volume 1: Issues, proximate, and root causes (Draft). Phuket, Thailand: Bay of Bengal Large Marine Ecosystem Project.

Carpenter, S., Walker, B., Anderies, J.M., and Abel, N., 2001. From metaphor to measurement: Resilience of what to what? Ecosystems, 4 (8), 765-781.

Castleden, H., Garvin, T., and Huu-ay-aht First Nation, 2008. Modifying Photovoice for communitybased participatory Indigenous research. Social Science \& Medicine, 66(6), 1393-1405.

Cinner, J.E., McClanahan, T.R., Daw, T.M., Graham, N.A.J., Maina, J., Wilson, S.K., and Hughes, T.P., 2009. Linking social and ecological systems to sustain coral reef fisheries. Current Biology, 19 (3), 206-212.

Dearden, P., Bennett, M., and Rollins, R. (2006). Dive specialization in Phuket: Implications for reef conservation. Environmental Conservation, 33 (4), 353-363.

DOT, 2009. Tourism Statistics (online), Department of Tourism. Available from: http://tourism.go.th/2010/th/statistic/tourism.php?cid=27 [Accessed on 18 January 2011].

Esser, L., 2010. Tools and Considerations to Integrate Climate Considerations into the Management of Mangrove Ecosystems: The Case of Kapoe Estuary, Ranong, Thailand. Thesis (MSc). Imperial College of London, London.

Gotschi, E., Delve, R., and Freyer, B., 2009. Participatory photography as a qualitative approach to obtain insights into farmer groups. Field Methods, 21 (3), 290-308.

Graybill, J., 2011. "It's all changing, but it isn't global climate change": Narratives about vulnerability and resilience in sub-Arctic Kamchatka. Conference presentation at the American Association of Geographers AGM, Seattle, USA, 12-16 April 2011.

Harper, D., 2003. Framing photographic ethnography: A case study. Ethnography, 4 (2), 241-266.

Hergenrather, K.C., Rhodes, S.D., Cowan, C.A., Bardhoshi, G., and Pula, S., 2009. Photovoice as community-based participatory research: A qualitative review. American Journal of Health Behavior, 33 (6), 683-698.

Juntarashote, K., 2005. Country report for BOBLEME Programme: Thailand. Phuket, Thailand: BOBLME.

Lemelin, R.H., Wiersma, E., Beaulieu, M., Trapper, L., Trapper, P., and Kapashesit, R., 2011. Picture if you will, climate change from a local perspective. Presentation at the Seventh International Congress of the Arctic Social Sciences (ICASS VII), Akureyri, Iceland, 22-26 June 2011. 
A Picture of Change 18

Lunn, K. E., and Dearden, P., 2006. Fishers' needs in marine protected area zoning: A case study from Thailand. Coastal Management, 34 (2), 183-198.

Marshall, N.A., Marshall, P.A., Tamelander, J., Obura, D., Malleret-King, D., and Cinner, J.E., 2009. A framework for social adaptation to climate change: Sustaining tropical coastal communitites and industries. Gland, Switzerland: IUCN.

Neuman, W.L., 2000. Social research methods: Qualitative and quantitative approaches (4th edition). Boston, MA: Allyn and Bacon.

Panjarat, S., 2008. Sustainable fisheries in the Andaman Sea Coast of Thailand. New York: Division for Ocean Affairs and the Law of the Sea, Office of Legal Affairs, The United Nations. $119 \mathrm{p}$.

Prasertcharoensuk, R., Shott, J., Sirisook Weston, D., and Ronarongpairee, W., 2010. Time for a sea change: A study of the effectiveness of biodiversity conservation measures and marine protected areas along southern Thailand's Andaman Sea coastline. SUMADRA Monograph. Chennai, India: International Collective in Support of Fishworkers.

Parry, M.L., and IPCC, 2007. Climate change 2007: Impacts, adaptation and vulnerability. Contribution of Working Group II to the fourth assessment report of the Intergovernmental Panel on Climate Change. Cambridge, New York: Cambridge University Press.

Phogsuwan, N. and PMBC, 2011. Preliminary report of the effect of coral bleaching in 2010. Phuket, Thailand: Marine and Coastal Biology and Ecology Unit, Phuket Marine Biological Center.

Prins, E., 2010. Participatory photography: A tool for empowerment or surveillance? Action Research, 8 (4), 426-443.

Rose, G., 1993. Feminism and Geography: The Limits of Geographical Knowledge. Minneapolis: University of Minnesota Press.

Sadoway, D.T., 2002. Searching for antidotes to globalization: Local institutions at Mongolia's sacred Bogd Khan Mountain. Thesis (Master's). Simon Fraser University, Vancouver, Canada.

Sielert, H., and Sangchan, S., 2001. Small-scale fishery in Southeast Asia: A case study in southern Thailand. RAP Publication. Bangkok, Thailand: FAO Regional Office for Asia and the Pacific. 63 p.

START, 2010. Preparation of climate change scenarios for climate change impact assessment in Thailand. Bangkok, Thailand: Southeast Asia START Regional Centre.

START and WWF, 2008. Climate change impacts in Krabi Province, Thailand. Bangkok, Thailand: Southeast Asia START Regional Center/WWF. 71 p.

Swyngeduow, E., 2011. Climate change and development. Panel Presentation during Association of American Geographers AGM, Seattle, USA, 12-16 April 2011.

Unnikrishnan, A.S., \& Shankar, D., 2007. Are sea-level-rise trends along the coasts of the north Indian Ocean consistent with global estimates? Global and Planetary Change, 57 (3-4), 301-307.

Wang, C., and Burris, M.A., 1997. Photovoice: Concept, methodology, and use for participatory needs assessment. Health Education \& Behavior, 24 (3), 369-387.

World Bank, 2006. Thailand Environment Monitor 2006: Marine and Coastal Resources. Washington, D.C.: World Bank.

World Heritage Nomination Document, 2010. Nomination document of The Andaman Bioregion of Thailand for UNESCO World Heritage Nomination. Bangkok, Thailand: Ministry of Natural Resources and Environment. 